\title{
Clinical, dermoscopic, and histopathological evaluations of patients with nail disorders
}

\author{
Mohammed Abu El-Hamd ${ }^{1}$, Fatma El-Zahraa Salah El-Deen Yassin ${ }^{1}$, Nehal Hussein Abd \\ El-hamid ${ }^{1}$, and Reham Ezz El-Dawla El-Sharkawy ${ }^{1}$ \\ ${ }^{1}$ Sohag University
}

March 10, 2021

\begin{abstract}
Objective: This study aimed to assess the possible role of dermoscopy in the diagnosis of different nail disorders compared with the clinical and histopathological diagnosis. Methods: This study included 104 patients with any nail disorders of both sex and any age. All the patients were subjected to a detailed medical history taken, clinical general examination, clinical and dermoscopic examinations of 20 nails. Potassium hydroxide examination was used to examine all patients with suspicious of onychomycosis. Histopathological evaluation was used to examine of clinically ambiguous nail disorders. Results: The most common nail diseases were onychomycosis $(54.81 \%)$ followed by nail psoriasis $(19.2 \%)$, and nail lichen planus (3.8\%). Conclusion: Clinical evaluation was an important in diagnosis of different nail diseases. Nail dermoscopy could confirm clinical diagnosis and help in getting an accurate diagnosis of nail diseases and guide in the management of nail diseases by permitting better visualization of nail structure and pathology. Histopathological examination provided the most definitive method in reaching an accurate diagnosis due to it could provide etiologic, diagnostic, and prognostic information. There was good agreement between clinical, dermoscopic, and histopathological examinations for accurate diagnosis of different nail diseases.
\end{abstract}

\section{Hosted file}

Main Text.pdf available at https://authorea.com/users/400773/articles/513058-clinicaldermoscopic-and-histopathological-evaluations-of-patients-with-nail-disorders 

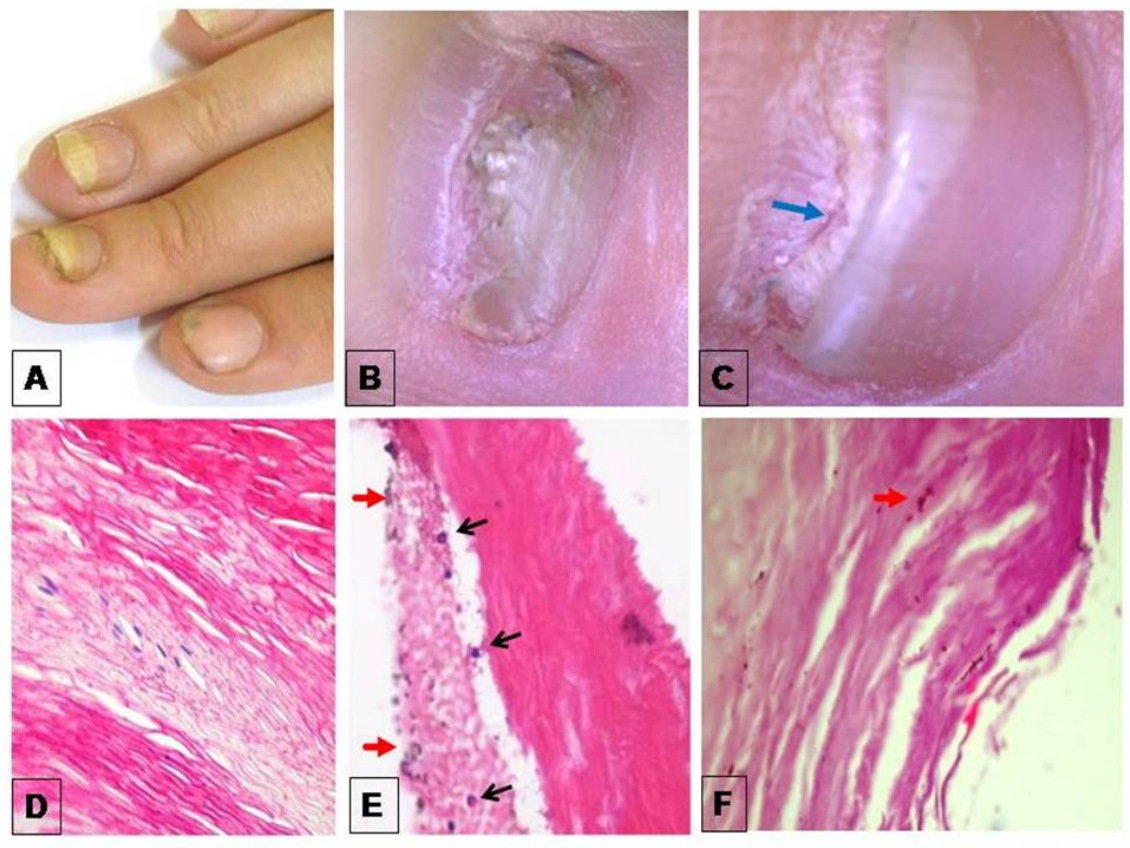

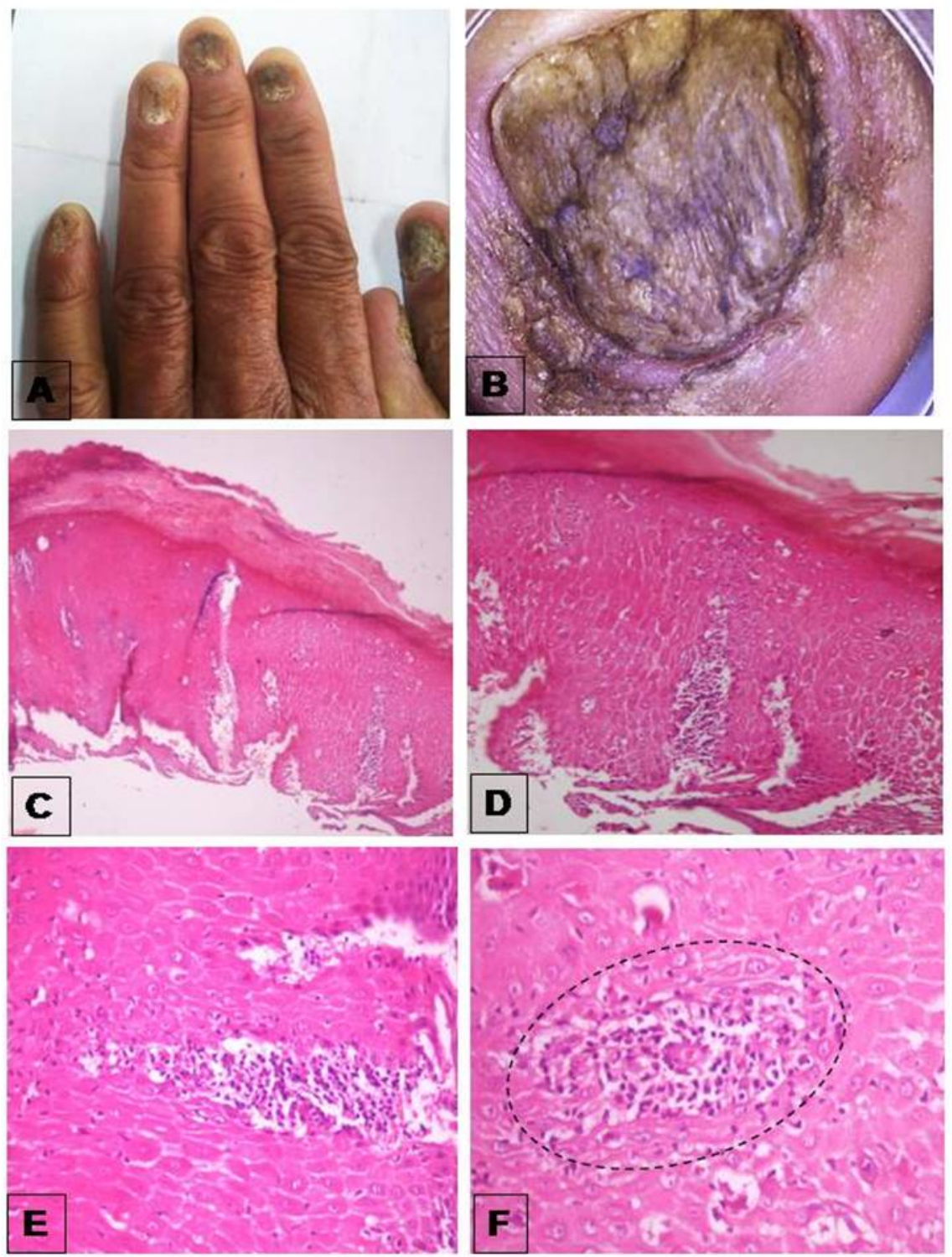

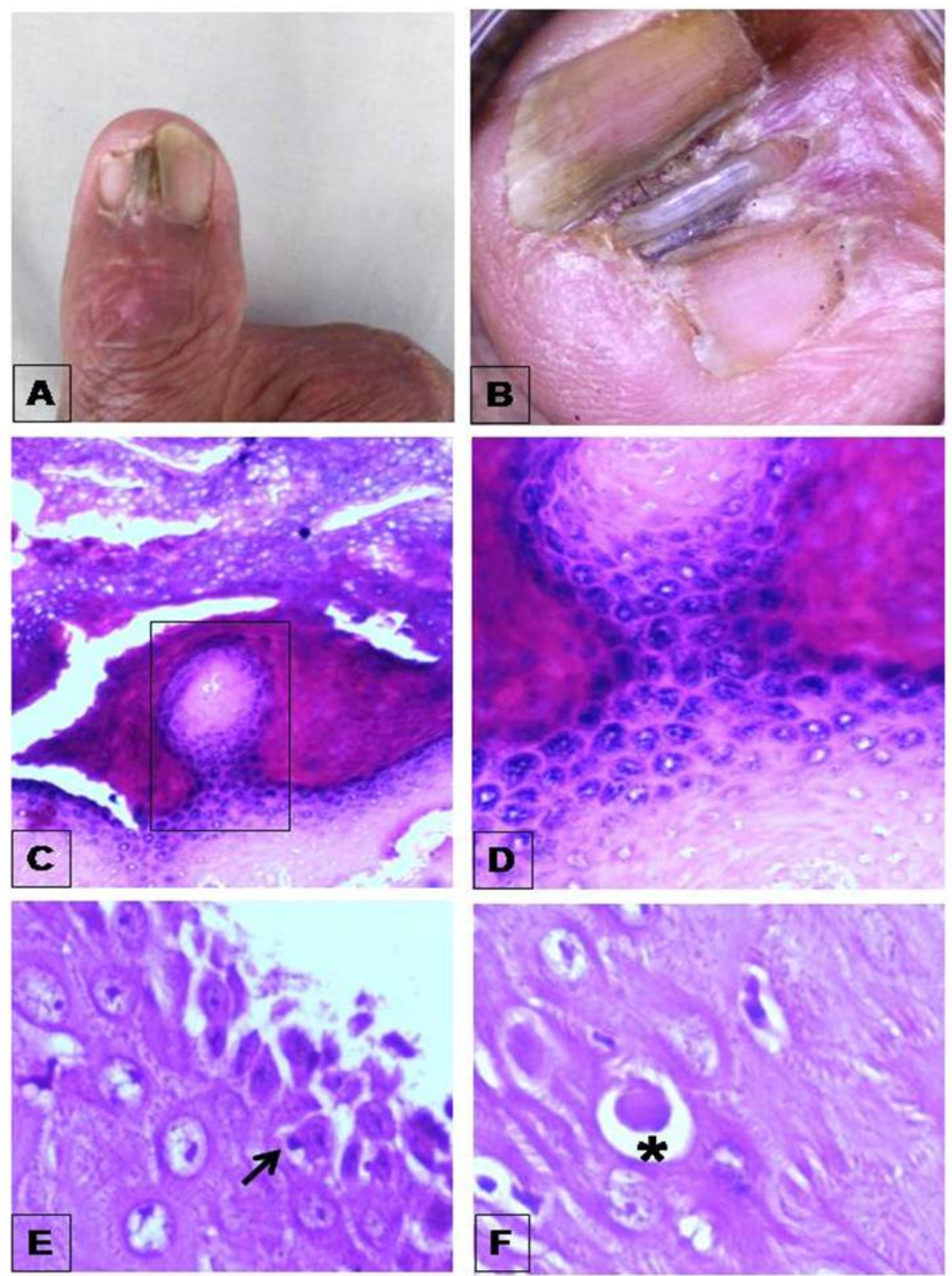

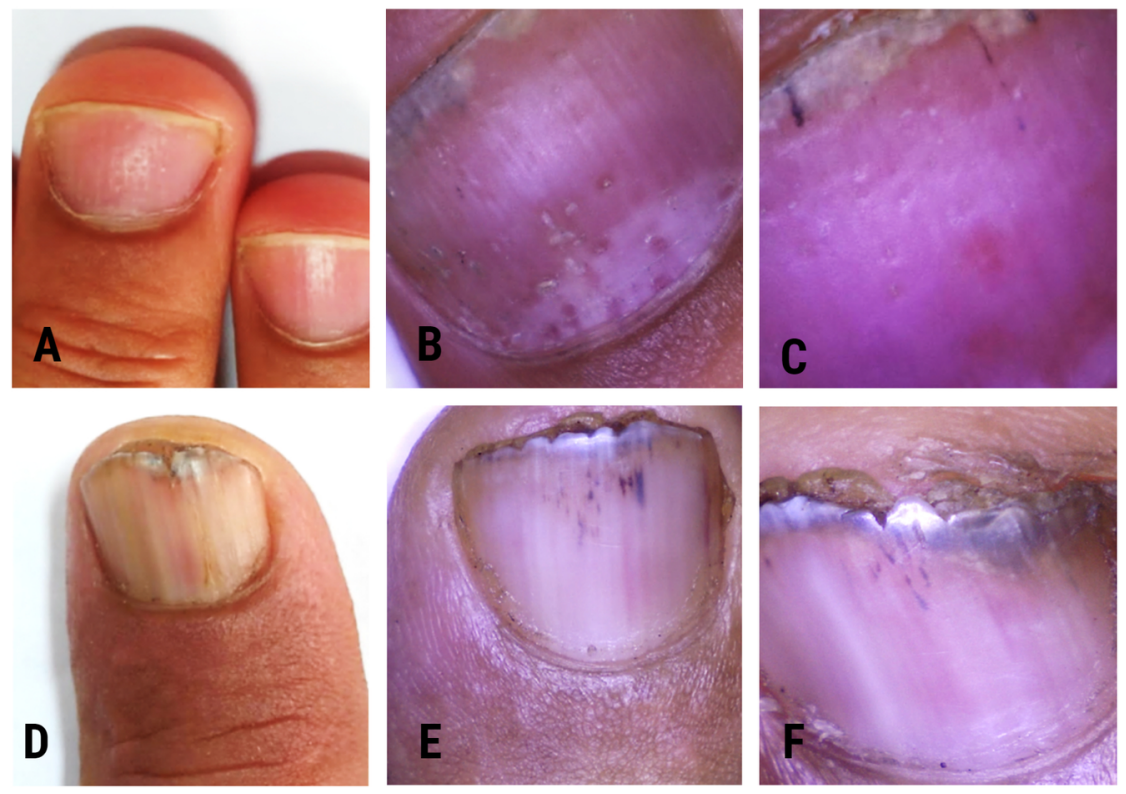